02

\title{
Роль состояний переноса заряда „лиганд-металл“ в процессах возбуждения люминесценции индолкарбоксилатов европия
}

\author{
(C) В.И. Царюк, К.П. Журавлев \\ Институт радиотехники и электроники им. В.А. Котельникова РАН, \\ 141190 Фрязино, Московская обл., Россия \\ e-mail: kpz225@mail.ru
}

Поступила в редакцию 30.06.2021 г.

В окончательной редакции 30.06.2021 г.

Принята к публикации 14.07.2021 г.

\begin{abstract}
Исследована передача энергии возбуждения люминесценции в индол-3-карбоксилатах, индол-3-ацетатах и индол-3-пропионатах европия и тербия, а также в тройных индолкарбоксилатах европия и тербия, содержащих молекулы 1,10-фенантролина и 2,2'-бипиридина. Рассмотрены спектры возбуждения люминесценции, времена жизни состояний ${ }^{5} D_{0}\left(\mathrm{Eu}^{3+}\right)$ и ${ }^{5} D_{4}\left(\mathrm{~Tb}^{3+}\right)$ и интенсивность люминесценции. Продемонстрирована решающая роль состояний переноса заряда „лиганд-металл“ в тушении люминесценции ароматических карбоксилатов европия, содержащих $\pi$-избыточный пиррольный или индольный фрагмент. Для большинства соединений европия характерно тушение, обусловленное опустошением ${ }^{5} D_{0}$-уровня иона $\mathrm{Eu}^{3+}$ через низкоэнергетическое состояние переноса заряда ,лиганд-металл“. Но в некоторых тройных соединениях состояние переноса заряда, будучи более высокоэнергетическим, участвует в безызлучательной дезактивации возбужденных электронных состояний лиганда.
\end{abstract}

Ключевые слова: люминесценция, $\mathrm{Eu}^{3+}, \mathrm{Tb}^{3+}$, индолкарбоксилат, $\pi$-избыточный гетероцикл.

DOI: $10.21883 /$ OS.2022.01.51899.26-21

\section{Введение}

В координационных соединениях легко восстанавливаемых ионов лантанидов $\left(\mathrm{Eu}^{3+}, \mathrm{Yb}^{3+}, \mathrm{Sm}^{3+}, \mathrm{Tm}^{3+}\right)$ электронная плотность наиболее высокой заполненной орбитали „мягкого“ донорного лиганда может смещаться к иону $\mathrm{Ln}^{3+}$ с образованием низкоэнергетических состояний переноса заряда „лиганд-металл“ (LMCT), которые нередко отвечают за тушение люминесценции [1-3]. С помощью теоретического моделирования процессов тушения комплексов лантанидов при различных относительных энергиях электронных состояний лиганда, состояния LMCT и $4 f$-состояний иона $\mathrm{Ln}^{3+}$ определены два доминирующих канала тушения: „Ln ${ }^{3+} \rightarrow$ LMCT-состояние“ и „лиганд $\rightarrow$ LMCT-состояние“ $[4,5]$. Безызлучательные процессы наиболее эффективны, когда состояние LMCT расположено вблизи наиболее низкого триплета лиганда [4]. Эффект тушения люминесценции координационных соединений европия при участии состояний LMCT лег в основу предложенных в работах [6,7] термосенсоров.

Состояния переноса заряда $2 p(\mathrm{O})-\mathrm{Eu}^{3+}$ идентифицированы в ряде ароматических карбоксилатов европия; рассмотрено также их влияние на передачу энергии к иону $\mathrm{Eu}^{3+}[8-10]$. При введении электронодонорных заместителей - $\mathrm{OCH}_{3},-\mathrm{OH},-\mathrm{NH}_{2}$ в орто- или пара-положение ароматического кольца бензоата европия смещение электронной плотности к иону $\mathrm{Eu}^{3+}$ приводит к образованию низкоэнергетических состояний LMCT [8]. Встраивание метиленовых групп - $\mathrm{CH}_{2}$ в карбоксилат, ослабляющих сопряжение между карбоксильной группой и ароматическим фрагментом, также может существенно понизить энергию состояния LMCT [9]. Появление избытка электронной плотности, способного сместиться к иону $\mathrm{Eu}^{3+}$, возможно в пирролсодержащих карбоксилатах, где сопряжены параллельно ориентированные орбитали неподеленной пары электронов атома азота и $\pi$-электронов ароматической системы лиганда. Недавно изучено участие состояния LMCT в тушении люминесценции пиррол-2-карбоксилата европия $\mathrm{Eu}(\mathrm{PCA})_{3} \cdot 3 \mathrm{H}_{2} \mathrm{O}\left(\left[\left\{\mathrm{Eu}(\mathrm{PCA})_{3} \cdot\left(\mathrm{H}_{2} \mathrm{O}\right)_{2}\right\} \cdot \mathrm{H}_{2} \mathrm{O}\right]_{n}\right)[10]$. Следует ожидать проявления аналогичного эффекта в индолкарбоксилатах европия с такой же взаимной ориентацией орбиталей лиганда, но с расширенной $\pi$-сопряженной ароматической системой. К явлениям такой же природы относится и эффективное тушение флуоресценции растворов индолов ионами $\mathrm{Eu}^{3+}$ и $\mathrm{Yb}^{3+}$ по сравнению с другими $\mathrm{Ln}^{3+}[11]$.

В настоящей работе рассмотрены особенности возбуждения люминесценции индол-3-карбоксилатов, индол-3-ацетатов и индол-3-пропионатов европия и тербия, в том числе с дополнительными лигандами: 1,10-фенантролином и 2,2'-бипиридином. Показано, что в соединениях европия определяющая роль в передаче энергии возбуждения к иону $\mathrm{Eu}^{3+}$ и тушении люминесценции принадлежит низкоэнергетическому состоянию LMCT. Проводится сравнение с пиррол-2-карбоксилатами и пиридинкарбоксилатами европия и тербия. Обсуждается влияние метиленовых мостиков на строение соединений и на передачу энергии возбуждения к иону $\mathrm{Ln}^{3+}$.

Известны лишь отдельные спектроскопические и рентгеноструктурные исследования пиррол- и индол- 
карбоксилатов лантанидов [12-15]. В то же время значительное число работ посвящено изучению пирролсодержащих карбоксилатов других металлов и карбоновых кислот с пиррольным фрагментом [16-21]. Интерес к этим соединениям обусловлен тем, что многие биологически важные соединения, такие как гемоглобин, хлорофилл, витамин В12 и ряд гормонов, включают фрагменты пиррола или индола. Производные индола, индолкарбоновые кислоты и соответствующие комплексы металлов, в том числе комплексы лантанидов $[13,15]$, проявляют противовоспалительную, антибактериальную, антивирусную, антиоксидантную активности [22,23].

\section{Экспериментальная часть}

Исследованы индол-3-карбоксилаты $\operatorname{Ln}(\mathrm{ICA})_{3} \cdot 3.5 \mathrm{H}_{2} \mathrm{O}$ $(\mathbf{1}, \mathbf{1 a})$, индол-3-ацетаты $\mathrm{Ln}(\mathrm{IAA})_{3} \cdot 1.5 \mathrm{H}_{2} \mathrm{O}(\mathbf{2}, \mathbf{2 a})$ и индол-3-пропионаты $\operatorname{Ln}(\mathrm{IPA})_{3} \cdot \mathrm{H}_{2} \mathrm{O}(\mathbf{3}, \mathbf{3 a})(\mathrm{Ln}=\mathrm{Eu}, \mathrm{Tb})$, a также тройные соединения с 1,10-фенантролином (Phen) и 2,2'-бипиридином (Вру): $\mathrm{Eu}(\mathrm{ICA})_{3} \cdot$ Вру (4), $\mathrm{Tb}(\mathrm{ICA})_{3} \cdot$ Bpy $\quad(5), \quad \mathrm{Tb}(\mathrm{ICA})_{3} \cdot$ Phen $\cdot \mathrm{H}_{2} \mathrm{O} \quad(6)$, $\mathrm{Eu}(\mathrm{IAA})_{3} \cdot$ Phen (7), Tb(IAA) $)_{3} \cdot \operatorname{Phen}(\mathbf{8}), \mathrm{Eu}(\mathrm{IPA})_{3} \cdot \operatorname{Bpy}(\mathbf{9})$. Соединения в виде порошков синтезированы по стандартным методикам [10]. Перечисленные соединения сведены в таблицу. На рис. 1 представлены формулы лигандов, включающих пиррольный фрагмент. Сравнение спектроскопических характеристик изоструктурных соединений легко восстанавливаемого иона $\mathrm{Eu}^{3+}$ и легко окисляемого иона $\mathrm{Tb}^{3+}$ (в частности, 1 и $\mathbf{1 a}, 2$ и 2a, 3 и 3a) облегчает идентификацию состояний LMCT и анализ передачи энергии возбуждения в соединениях европия. Рассмотрены спектры люминесценции и возбуждения люминесценции соединений европия и тербия, времена жизни электронных состояний ${ }^{5} D_{0}$ $\left(\mathrm{Eu}^{3+}\right)$ и ${ }^{5} D_{4}\left(\mathrm{~Tb}^{3+}\right)$ и интегральная интенсивность люминесценции, спектры фосфоресценции соединений гадолиния, а также колебательные ИК спектры.

Спектры люминесценции и возбуждения соединений европия и тербия получали с помощью спектрометров ЛОМО ИСП-51 с регистрирующей фотоэлектронной кассетой ФЭК-2/3648 и SLM Aminco SPF 500 при 77 и 295 K. Регистрацию спектров возбуждения осуществляли при мониторинге области наиболее интенсивных линий переходов ${ }^{5} D_{0}-{ }^{7} F_{2}\left(\mathrm{Eu}^{3+}\right)$ и ${ }^{5} D_{4}-{ }^{7} F_{5}\left(\mathrm{~Tb}^{3+}\right)$. Спектры фосфоресценции соединений гадолиния и времена жизни возбужденных электронных состояний ${ }^{5} D_{0}\left(\mathrm{Eu}^{3+}\right)$ и ${ }^{5} D_{4}\left(\mathrm{~Tb}^{3+}\right)$ измеряли с помощью установки на основе монохроматора ЛОМО УМ-2 с высокочувствительным фотоумножителем Hamamatsu H6780-20. Источниками возбуждения люминесценции служили ртутная лампа высокого давления ДРШ-250 и светодиод Nichia High-Power LED NCSU033B. Люминесценцию возбуждали длиной волны $365 \mathrm{~nm}$ УФ излучения. Значения энергии наиболее низкого триплетного состояния $T_{1}$ лигандов ICA, IAA и IPA, равные $\sim 23400, \sim 21800$ и $\sim 21000 \mathrm{~cm}^{-1}$ соответственно, определены по корот- коволновому краю полосы фосфоресценции двойных соединений гадолиния, зарегистрированной при $77 \mathrm{~K}$ с задержкой по времени. Приблизительные значения энергии нижнего возбужденного синглетного состояния $S_{1}$ индолкарбоксилата, равные $32000-32800 \mathrm{~cm}^{-1}$ в двойных соединениях и $25500-27000 \mathrm{~cm}^{-1}$ в тройных, получены из длинноволнового края полосы лиганда в спектрах возбуждения соединений тербия или европия при $77 \mathrm{~K}$. Эти значения энергии относятся к бесфононным 0-0-переходам в широких полосах лигандов $T_{1}-S_{0}$ и $S_{0}-S_{1}$, обусловленных сильным электронноколебательным взаимодействием. Для анализа процессов высвечивания состояний ${ }^{5} D_{0}\left(\mathrm{Eu}^{3+}\right)$ и ${ }^{5} D_{4}\left(\mathrm{~Tb}^{3+}\right)$ применяли моно- и биэкспоненциальную подгонку кинетики затухания с помощью программы Origin 8.0. Для большинства соединений экспериментальные времена жизни лучше соответствовали биэкспоненциальному закону затухания, чем моноэкспоненциальному. В этих случаях определяли среднее время жизни [24]. Отклонения от моноэкспоненциального характера высвечивания обычно связаны с влиянием неконтролируемых примесей и/или со сложными процессами передачи энергии возбуждения на ион $\mathrm{Ln}^{3+}$. При оценке интегральных интенсивностей по спектрам люминесценции образцы соединений находились в строго одинаковых условиях. Колебательные ИК спектры эмульсий соединений в вазелиновом и фторированном маслах регистрировали на спектрофотометре Nicolet Magna 750 FTIR при 295 K.

\section{Результаты и их обсуждение}

\section{Строение индолкарбоксилатов лантанидов и осо- бенности люминесценциии}

В соответствии с экспериментальными данными структуры соединений построены из молекул, состоящих из атома Ln, трех анионов индолкарбоксилата, координированных металлом через атомы кислорода, и молекул воды. В тройных соединениях вместо молекул воды присутствует молекула гетероциклического диимина, координированная через два атома азота. Судя по колебательным ИК спектрам, двойные соединения европия и тербия с каждой из трех индолкарбоновых кислот (1 и 1a, 2 и 2a, 3 и 3a) являются изоструктурными, как и пиррол-2-карбоксилаты [10]. В процессе синтезов расширенной серии тройных соединений выявлена тенденция для лигандов IAA и IPA образовывать изоструктурные пары комплексов $\mathrm{Eu}$ и $\mathrm{Tb}$, в то время как для лиганда ICA такая тенденция не прослеживается. Все исследуемые в настоящей работе тройные индолкарбоксилаты имеют разное строение.

Интерпретация ИК спектров, представленных на рис. 2, проведена с учетом результатов изучения индолкарбоновых кислот и соответствующих комплексов с металлами [17-20,25]. Интенсивные полосы в области $1400-1600 \mathrm{~cm}^{-1}$ относятся к симметричным $v_{\mathrm{s}}\left(\mathrm{COO}^{-}\right)$ и антисимметричным $v_{\text {as }}\left(\mathrm{COO}^{-}\right)$валентным колебаниям 
<smiles>O=C(O)c1ccc[nH]1</smiles>

Pyrrole-2-carboxylic (PCA)<smiles>O=C(O)c1c[nH]c2ccccc12</smiles>

Indole-3-carboxylic (ICA)<smiles>O=C(O)Cc1c[nH]c2ccccc12</smiles>

Indole-3-acetic (IAA)<smiles>CCc1c[nH]c2ccccc12</smiles>

Indole-3-propionic (IPA)

Рис. 1. Структурные формулы пиррол- и индолкарбоновых кислот.
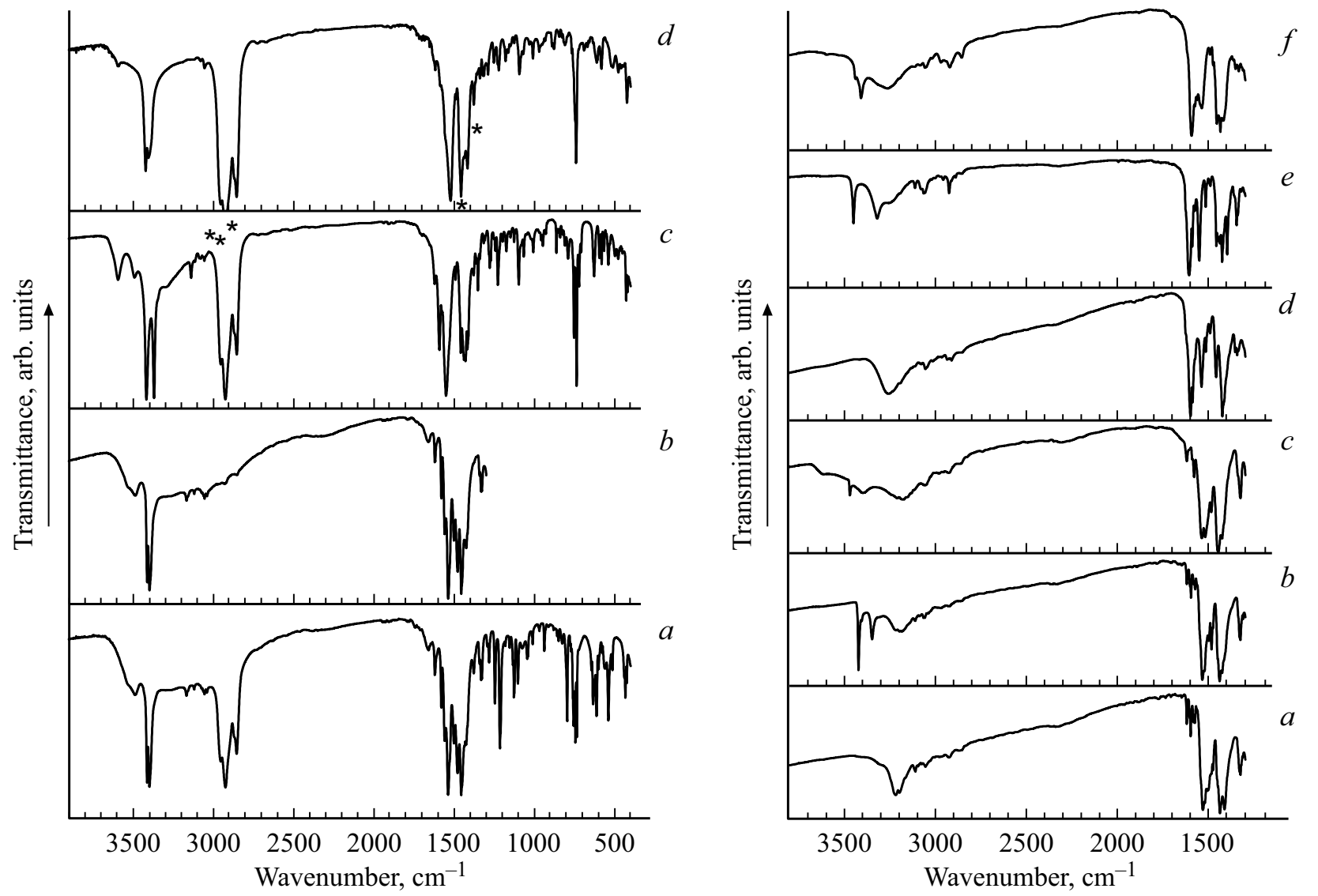

Рис. 2. Колебательные ИК спектры при $295 \mathrm{~K}:$ (слева) $\mathrm{Eu}(\mathrm{ICA})_{3} \cdot 3.5 \mathrm{H}_{2} \mathrm{O} \quad(\mathbf{1}) \quad(a, b), \quad \mathrm{Eu}(\mathrm{IAA})_{3} \cdot 1.5 \mathrm{H}_{2} \mathrm{O} \quad(\mathbf{2}) \quad(c)$, $\mathrm{Eu}(\mathrm{IPA})_{3} \cdot \mathrm{H}_{2} \mathrm{O}(3)(d)$; (справа) $\mathrm{Eu}(\mathrm{ICA})_{3} \cdot \operatorname{Bpy}(4)(a), \mathrm{Tb}(\mathrm{ICA})_{3} \cdot \mathrm{Bpy}(\mathbf{5})(b), \mathrm{Tb}(\mathrm{ICA})_{3} \cdot$ Phen $\cdot \mathrm{H}_{2} \mathrm{O}(\mathbf{6})(c), \mathrm{Eu}(\mathrm{IAA})_{3} \cdot \mathrm{Phen}(\mathbf{7})(d)$, $\mathrm{Tb}(\mathrm{IAA})_{3} \cdot \operatorname{Phen}(\mathbf{8})(e), \mathrm{Eu}(\mathrm{IPA})_{3} \cdot$ Вру $(9)(f)$. Спектры $a, c$ и $d$ в левой панели - слои в вазелиновом масле (звездочками помечены полосы вазелинового масла), остальные спектры - слои во фторированном масле.

координированной карбоксильной группы и сложным валентным колебаниям ароматических колец. Небольшое расщепление $v\left(\mathrm{COO}^{-}\right)$, составляющее $\sim 100 \mathrm{~cm}^{-1}$ в большинстве соединений, указывает на эквивалентность эффективных зарядов на атомах кислорода и бидентатно-циклическую и/или бидентатно-мостиковую координацию карбоксильных групп. Увеличение расщепления до $\sim 170 \mathrm{~cm}^{-1}$ с бл́шшим числом компонент $v_{\mathrm{s}}\left(\mathrm{COO}^{-}\right)$и $v_{\mathrm{as}}\left(\mathrm{COO}^{-}\right)$в тройных соединениях 7, 8 и 9 с лигандами IAA и IPA, предположительно, связано с

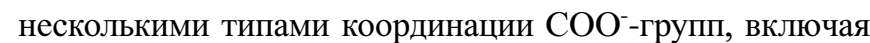
тридентатную мостиково-циклическую.

Полосы в области $2800-3700 \mathrm{~cm}^{-1}$ относятся к симметричным и антисимметричным валентным колебаниям координированных и внешнесферных молекул воды $v\left(\mathrm{H}_{2} \mathrm{O}\right)$, валентным колебаниям $v(\mathrm{~N}-\mathrm{H})$ и $v(\mathrm{C}-\mathrm{H})$. Две сильные линии при $3400 \mathrm{~cm}^{-1}$ в спектрах двойных соединений свидетельствуют о том, что $\mathrm{N}-\mathrm{H}$-группа является свободной и не участвует в образовании водородных связей. Появление двух компонент $v(\mathrm{~N}-\mathrm{H})$ 
обусловлено неэквивалентностью лигандов. Широкая полоса в области $2600-3650 \mathrm{~cm}^{-1}$ спектров двойных соединений относится к сети водородных связей, образованных молекулами воды. Интенсивность этой полосы согласуется с количеством молекул воды в соединениях.

Появление уширенной полосы при $3200 \mathrm{~cm}^{-1}$ в тройных соединениях и ослабление или исчезновение узких линий $\mathrm{N}-\mathrm{H}-г$ руппы говорит об образовании водородных связей с атомами кислорода карбоксильных групп N-H. . О. В соединениях присутствуют как связанные, так и несвязанные $\mathrm{N}-\mathrm{H}-г$ руппы, за исключением индолкарбоксилата $\mathrm{Eu}(\mathrm{ICA})_{3} \cdot \mathrm{Bpy}(4)$ и индолацетата $\mathrm{Eu}(\mathrm{IAA})_{3} \cdot$ Phen (7), где в водородные связи

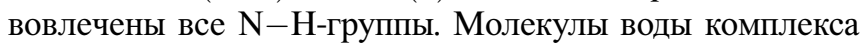
$\mathrm{Tb}(\mathrm{ICA})_{3} \cdot$ Phen $\cdot \mathrm{H}_{2} \mathrm{O}$ (6) также образуют водородные связи.

Максимально возможное число штарковских компонент электронных переходов в спектрах люминесценции индолкарбоксилатов европия и разный характер расщепления (рис. 3) свидетельствуют о низкой симметрии ближайшего окружения иона $\mathrm{Ln}^{3+}$ с разными типами искажений. В исследуемых индол-3-ацетатах и индол-3-пропионатах метиленовые мостики - $\mathrm{CH}_{2}$, „отодвигают“ объемный ароматический фрагмент от иона $\mathrm{Ln}^{3+}$, что уменьшает его стерическое влияние на ближайшее окружение $\mathrm{Ln}^{3+}$ и приводит к понижению искажений кристаллического поля аналогично фенили нафтилкарбоксилатам лантанидов $[9,26]$. На это указывает уменьшение интегральной интенсивности сверхчувствительного электродипольного перехода ${ }^{5} D_{0}-{ }^{7} F_{2}$ по отношению к интенсивности магнитно-дипольного ${ }^{5} D_{0}-{ }^{7} F_{1}$-перехода. Уменьшается также скорость естественных излучательных процессов, что обусловливает удлинение времен жизни состояний ${ }^{5} D_{0}\left(\mathrm{Eu}^{3+}\right)$ и ${ }^{5} \mathrm{D}_{4}\left(\mathrm{~Tb}^{3+}\right)$ до $1.27-1.74 \mathrm{~ms}$ в тройных соединениях 7 , 8 и 9 с лигандами IAA и IPA по сравнению с временами жизни, равными $0.67-0.90 \mathrm{~ms}$, в соединениях 4, 5 и 6 с лигандом ICA (таблица).

Другое проявление влияния метиленовых мостиков на характеристики индолкарбоксилатов относится к тушению люминесценции $\mathrm{Eu}^{3+}$ через состояния LMCT. „Разъединение“ $\pi-\pi$-системы ароматического карбоксилата группами - $\mathrm{CH}_{2}$ - может привести к смещению электронной плотности карбоксильной группы к иону $\mathrm{Eu}^{3+}$ с образованием низкоэнергетических состояний LMCT, как наблюдалось в фенил- и нафтилкарбоксилатах европия $[9,26]$. Если в индол-3-карбоксилатах европия электронная плотность беспрепятственно смещается с $\pi$-избыточного индольного фрагмента к иону $\mathrm{Eu}^{3+}$, то в индол-3-ацетатах и индол-3-пропионатах такое смещение блокируется метиленовыми мостиками. Но при этом блокировка вызывает смещение к $\mathrm{Eu}^{3+}$ электронной плотности, имеющейся на карбоксильной группе.

Низкая интенсивность люминесценции двойных соединений лантанидов объясняется малой вероятностью интеркомбинационной конверсии и соответственно слабым заселением триплета из-за большого энергетиче-

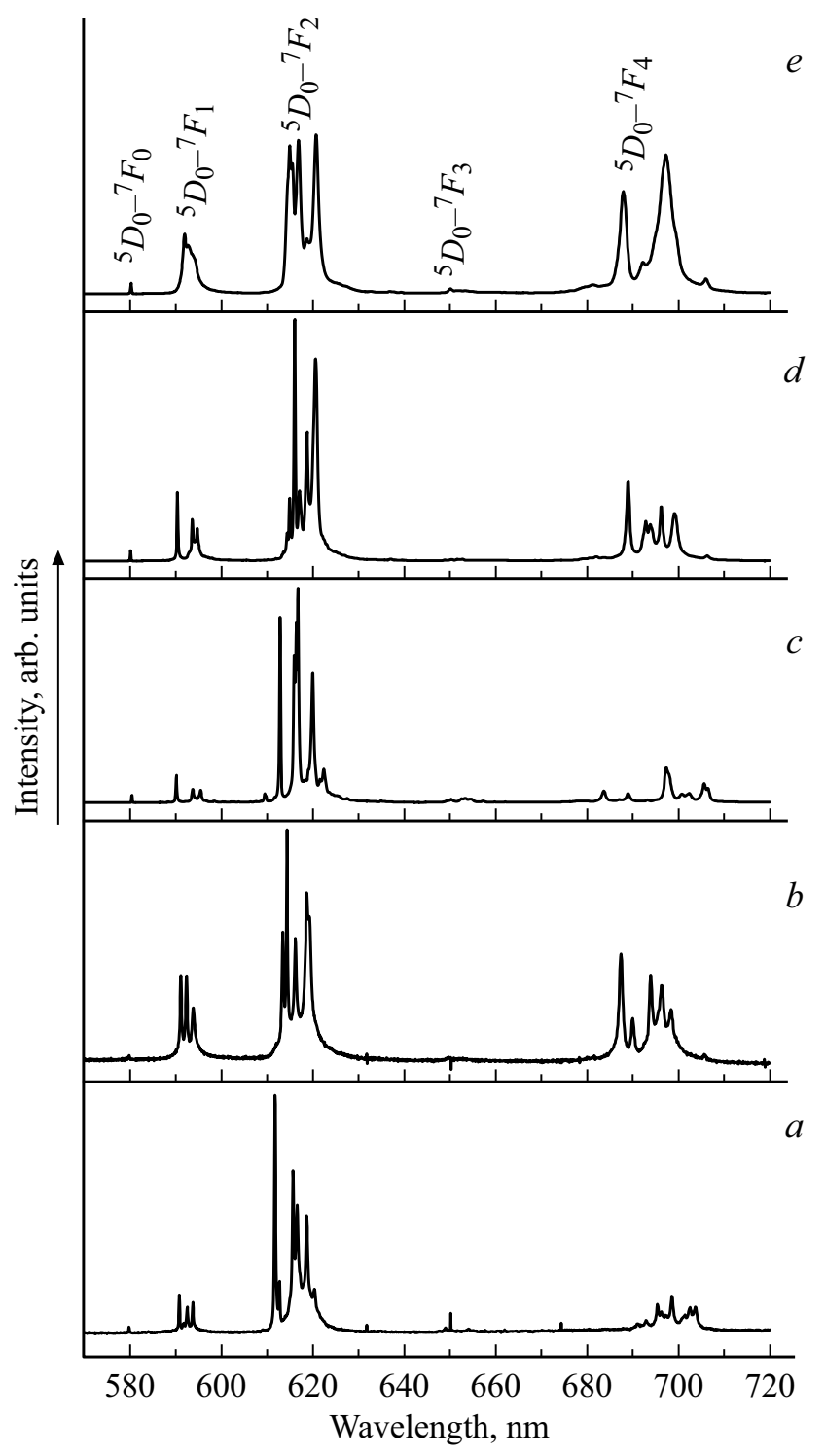

Рис. 3. Спектры люминесценции $\mathrm{Eu}(\mathrm{ICA})_{3} \cdot 3.5 \mathrm{H}_{2} \mathrm{O}(\mathbf{1})(a)$, $\mathrm{Eu}(\mathrm{IAA})_{3} \cdot 1.5 \mathrm{H}_{2} \mathrm{O} \quad(2) \quad(b), \quad \mathrm{Eu}(\mathrm{ICA})_{3} \cdot \mathrm{Bpy} \quad(4) \quad(c)$, $\mathrm{Eu}(\mathrm{IAA})_{3} \cdot$ Phen $(7)(d), \mathrm{Eu}(\mathrm{IPA})_{3} \cdot$ Вру $(9)(e)$ при $77 \mathrm{~K}$.

ского интервала $S_{1}-T_{1}$, возрастающего от $\sim 8600$ до $\sim 10200$ и $\sim 11800 \mathrm{~cm}^{-1}$ в соединениях с лигандами ICA, IAA и IPA, высокой скоростью многофононной безызлучательной релаксации из-за присутствия молекул воды, а также, как будет показано ниже для соединений европия, тушащим влиянием низкоэнергетических состояний LMCT. Более высокая на один-два порядка интенсивность люминесценции тройных соединений лантанидов при $77 \mathrm{~K}$ обусловлена наличием широкой полосы поглощения лигандов в области используемого возбуждения $365 \mathrm{~nm}$, меньшими интервалами $S_{1}-T_{1}$ в обоих лигандах и соответственно более высокой вероятностью интеркомбинационной конверсии, отсутствием тушащих молекул воды и, судя по низкотемпературным 
Исследуемые индолкарбоксилаты европия и тербия, времена жизни $\tau(\mathrm{ms})$ состояний ${ }^{5} D_{0}\left(\mathrm{Eu}^{3+}\right)$ и ${ }^{5} D_{4}\left(\mathrm{~Tb}^{3+}\right)$ и изменение интенсивности люминесценции при повышении температуры от 77 до $295 \mathrm{~K}$. $\lambda_{\mathrm{exc}}=365 \mathrm{~nm}$

\begin{tabular}{|c|c|c|c|c|c|c|c|}
\hline № & Соединение & $\begin{array}{c}\tau_{77 \mathrm{~K}} \\
\left(\mathrm{Eu}^{3+}\right)\end{array}$ & $\begin{array}{r}\tau_{295 \mathrm{~K}} \\
\left(\mathrm{Eu}^{3+}\right)\end{array}$ & $\begin{array}{c}\tau_{77 \mathrm{~K}} \\
\left(\mathrm{~Tb}^{3+}\right)\end{array}$ & $\begin{array}{r}\tau_{295 \mathrm{~K}} \\
\left(\mathrm{~Tb}^{3+}\right)\end{array}$ & $\begin{array}{c}I_{295 \mathrm{~K}} / I_{77 \mathrm{~K}} \\
\left(\mathrm{Eu}^{3+}\right)\end{array}$ & $\begin{array}{l}I_{295 \mathrm{~K}} / I_{77 \mathrm{~K}} \\
\left(\mathrm{~Tb}^{3+}\right)\end{array}$ \\
\hline $1,1 a$ & $\mathrm{Ln}(\mathrm{ICA})_{3} \cdot 3.5 \mathrm{H}_{2} \mathrm{O}(\mathrm{Ln}=\mathrm{Eu}, \mathrm{Tb})$ & 0.51 & 0.22 & 0.71 & 0.70 & 0.24 & 1 \\
\hline $2,2 a$ & $\mathrm{Ln}(\mathrm{IAA})_{3} \cdot 1.5 \mathrm{H}_{2} \mathrm{O}(\mathrm{Ln}=\mathrm{Eu}, \mathrm{Tb})$ & 0.73 & $\sim 0.21$ & 1.09 & 1.06 & 0.06 & 0.5 \\
\hline $3,3 a$ & $\mathrm{Ln}(\mathrm{IPA})_{3} \cdot \mathrm{H}_{2} \mathrm{O}(\mathrm{Ln}=\mathrm{Eu}, \mathrm{Tb})$ & 0.90 & $\sim 0.16$ & 1.21 & 1.13 & 0.01 & 0.3 \\
\hline 4 & $\mathrm{Eu}(\mathrm{ICA})_{3} \cdot \mathrm{Bpy}$ & 0.67 & 0.63 & & & 0.05 & \\
\hline 5 & $\mathrm{~Tb}(\mathrm{ICA})_{3} \cdot \mathrm{Bpy}$ & & & 0.79 & 0.83 & & 2 \\
\hline 6 & $\mathrm{~Tb}(\mathrm{ICA})_{3} \cdot$ Phen $\cdot \mathrm{H}_{2} \mathrm{O}$ & & & 0.90 & 0.51 & & 0.1 \\
\hline 7 & $\mathrm{Eu}(\mathrm{IAA})_{3} \cdot \mathrm{Phen}$ & 1.27 & 0.40 & & & 0.01 & \\
\hline 8 & $\mathrm{~Tb}(\mathrm{IAA})_{3} \cdot$ Phen & & & 1.74 & $\sim 0.05$ & & 0.01 \\
\hline 9 & $\mathrm{Eu}(\mathrm{IPA})_{3} \cdot \mathrm{Bpy}$ & 1.56 & 1.19 & & & 0.04 & \\
\hline
\end{tabular}

спектрам возбуждения, отсутствием тушения с участием LMCT в соединениях европия.

\section{Времена жкизни ${ }^{5} D_{0}\left(E^{3+}\right)-u^{5} D_{4}\left(T^{3+}\right)$-состоя- ний}

Время жизни нижнего возбужденного излучательного состояния $\mathrm{Ln}^{3+}$ в координационных соединениях лантанидов может быть представлено как $\tau=1 /\left(k_{\mathrm{r}}+k_{\mathrm{vibr}}+k_{\mathrm{LMCT}}+k_{\mathrm{BT}}+k_{\mathrm{Ln}-\mathrm{Ln}}\right)$, где $k_{\mathrm{r}}-$ скорость естественного излучательного процесса, а остальные вклады в $\tau$ являются скоростями безызлучательных процессов [27]. $k_{\text {vibr }}$ относится к многофононной релаксации с участием высокочастотных валентных колебаний лигандов, $k_{\mathrm{LMCT}}$ описывает опустошение уровня $\mathrm{Ln}^{3+}$ через низкоэнергетическое состояние LMCT, $k_{\mathrm{BT}}-$ обратную передачу энергии с уровня $\mathrm{Ln}^{3+}$ на наиболее низкий триплет лиганда, $k_{\mathrm{Ln}-\mathrm{Ln}}-$ концентрационное тушение. Как правило, концентрационное тушение Ln-Ln в карбоксилатах, где расстояние Ln-Ln превышает $4 \AA$, пренебрежимо мало [10,28]. Скорости $k_{\mathrm{r}}$ и $k_{\mathrm{vibr}}$ не зависят существенно от температуры в используемом температурном интервале [1] в отличие от $k_{\mathrm{LMCT}}$ и $k_{\mathrm{BT}}$. Вклад $k_{\text {ВТ }}$ актуален только для некоторых исследуемых соединений тербия, где энергии триплетного состояния лиганда и состояния ${ }^{5} D_{4}$ достаточно близки. Следовательно, за сокращение времени жизни состояния ${ }^{5} D_{0}$ и соответственно за падение интенсивности люминесценции соединений европия, представленных в таблице, при повышении температуры должны отвечать процессы с участием LMCT, описываемые $k_{\mathrm{LMCT}}$. Влияние состояния LMCT на люминесценцию определяется как положением минимума потенциальной кривой этого состояния, так и формой кривой. Если энергия LMCT достаточно высока, то возможно участие этого состояния в опустошении электронных уровней лиганда, что приведет к уменьшению квантового выхода люминесценции, но не скажется на времени жизни ${ }^{5} D_{0}$-состояния $[5,26,29,30]$.

В двойных соединениях европия 1, 2, 3 и соединениях тербия 1a, 2a, 3a при $77 \mathrm{~K}$ время жизни $\tau$ последовательно увеличивается в ряду лигандов ICA, IAA, IPA (таблица), что в значительной степени связано с уменьше- нием числа молекул воды и соответственно понижением скорости многофононной релаксации. В соединениях с наибольшим содержанием воды: $\mathrm{Ln}(\mathrm{ICA})_{3} \cdot 3.5 \mathrm{H}_{2} \mathrm{O}$ (1, 1a), кроме существенного вклада $k_{\text {vibr }}$ в $\tau$, повышенный вклад в $\tau$ даст также $k_{\mathrm{r}}$ из-за искажений, внесенных стерическими затруднениями. Судя по спектрам возбуждения (рис. 4), в двойных соединениях европия при $77 \mathrm{~K}$ активен и вклад тушения с участием состояний переноса заряда $k_{\mathrm{LMCT}}$. Более продолжительное время жизни в соединениях тербия объясняется отсутствием этого канала тушения в дополнение к большему энергетическому интервалу между ${ }^{5} D_{\mathrm{J}^{-}}$и ${ }^{7} F_{\mathrm{J}}$-мультиплетами, обусловливающему меньшую величину многофононной релаксации.

Время жизни ${ }^{5} D_{4}$-состояния в соединениях тербия, за исключением $\mathrm{Tb}(\mathrm{ICA})_{3} \cdot \mathrm{Phen} \cdot \mathrm{H}_{2} \mathrm{O} \quad$ (6) и $\mathrm{Tb}(\mathrm{IAA})_{3}$. Phen (8), не меняется при повышении температуры или меняется слабо. В соединениях 6 и 8 наблюдается сокращение времени жизни при нагревании соответственно с 0.90 до $0.51 \mathrm{~ms}$ и с 1.74 до $\sim 0.05 \mathrm{~ms}$ и уменьшение интенсивности люминесценции. В 6 это связано с обратной передачей энергии возбуждения с ${ }^{5} D_{4}$-уровня $\left(\sim 20500 \mathrm{~cm}^{-1}\right)$ на триплет фенантролина $\left(\sim 21500 \mathrm{~cm}^{-1}[28], \Delta=\sim 1000 \mathrm{~cm}^{-1}\right)$, в то время как триплет ICA $\left(\sim 23400 \mathrm{~cm}^{-1}\right)$ лежит слишком высоко, чтобы участвовать в обратной передаче. В соединении 8 возможна обратная передача на триплеты обоих лигандов: Phen и IAA $\left(\sim 21800 \mathrm{~cm}^{-1}\right)$. В соединении $\mathrm{Tb}(\mathrm{ICA})_{3} \cdot$ Вру (5) триплет дополнительного лиганда Вру $\left(\sim 22500 \mathrm{~cm}^{-1}\right)$, как и ICA, расположен существенно выше уровня ${ }^{5} D_{4}$, поэтому обратная передача энергии возбуждения отсутствует.

Последовательное уменьшение времени жизни ${ }^{5} D_{0}$-состояния при $295 \mathrm{~K}$ по отношению к его значению при $77 \mathrm{~K}$ в ряду двойных соединений европия $\mathbf{1}$, 2, 3 указывает на понижение энергии активации ${ }^{5} D_{0} \rightarrow$ LMCT. Более резкое падение интенсивности люминесценции соединений европия при нагревании по сравнению с соединениями тербия также говорит об участии состояний LMCT в тушении первых. 

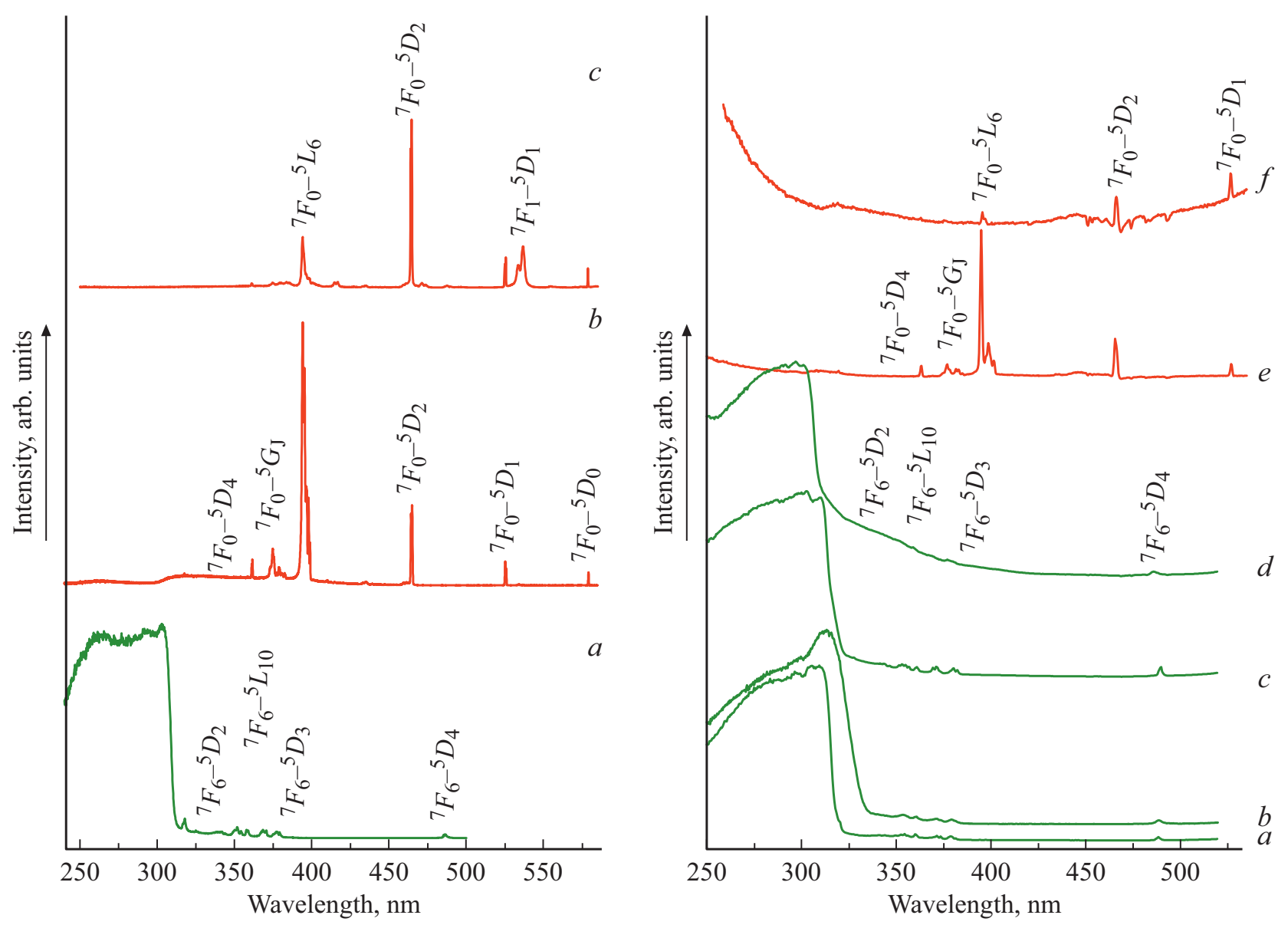

Рис. 4. Спектры возбуждения люминесценции: (слева) пирролкарбоксилатов $\mathrm{Tb}(\mathrm{PCA})_{3} \cdot 3 \mathrm{H}_{2} \mathrm{O}$ при $77 \mathrm{~K}(a)$ и $\mathrm{Eu}(\mathrm{PCA})_{3} \cdot 3 \mathrm{H}_{2} \mathrm{O}$ при $77(b)$ и $295 \mathrm{~K}(c)$; (справа) двойных индолкарбоксилатов $\mathrm{Tb}(\mathrm{ICA})_{3} \cdot 3.5 \mathrm{H}_{2} \mathrm{O}(\mathbf{1 a})$ при $77(a)$ и $295 \mathrm{~K}(b), \mathrm{Tb}(\mathrm{IAA})_{3} \cdot 1.5 \mathrm{H}_{2} \mathrm{O}(\mathbf{2 a})(c)$, $\mathrm{Tb}(\mathrm{IPA})_{3} \cdot \mathrm{H}_{2} \mathrm{O}(\mathbf{3 a})(d), \mathrm{Eu}(\mathrm{ICA})_{3} \cdot 3.5 \mathrm{H}_{2} \mathrm{O}(\mathbf{1})(e)$ и $\mathrm{Eu}(\mathrm{IAA})_{3} \cdot 1.5 \mathrm{H}_{2} \mathrm{O}(\mathbf{2})(f)$ при $77 \mathrm{~K}$.

В соединении $\mathbf{1}$ электронная плотность лиганда за счет ее избытка на индольном фрагменте смещается к иону $\mathrm{Eu}^{3+} \mathrm{c}$ образованием низкоэнергетического состояния LMCT. В соединениях 2 и 3 это смещение модифицировано метиленовыми мостиками, как описано выше.

$\mathrm{B}$ тройном соединении европия $\mathrm{Eu}(\mathrm{ICA})_{3}$. Bру (4) время жизни ${ }^{5} D_{0}$-состояния при повышении температуры меняется незначительно, в то время как интенсивность люминесценции сильно падает. Это свидетельствует о передаче энергии возбуждения с электронных состояний лиганда на состояние LMCT c eе дальнейшей безызлучательной релаксацией. В случае соединений $\mathrm{Eu}(\mathrm{IAA})_{3} \cdot$ Phen (7) и $\operatorname{Eu}(\mathrm{IPA})_{3} \cdot$ Bру (9) уменьшаются как время жизни состояния ${ }^{5} D_{0}$, так и интенсивность люминесценции, что связано с опустошением уровня ${ }^{5} D_{0}$ при участии состояния LMCT.

\section{Спектры возбуждения люминесценции}

Выводы о влиянии состояния LMCT на процессы тушения люминесценции индолкарбоксилатов европия, полученные из анализа данных таблицы, подтверждаются спектрами возбуждения люминесценции. Спектры, пред- ставленные на рис. 4, указывают на различие процессов передачи энергии в индол-3-карбоксилатах европия и тербия, как и в случае пиррол-2-карбоксилатов [10]. Эффективность возбуждения иона $\mathrm{Tb}^{3+}$ в тех и других через широкую полосу лиганда в УФ диапазоне является высокой по сравнению с эффективностью возбуждения иона $\mathrm{Eu}^{3+}$. Коротковолновая часть этой полосы относится к переходам $S_{0}-S_{1}\left(\pi-\pi^{*}\right)$. Длинноволновая часть полосы может относиться к внутрилигандному переносу заряда (ILCT), связанному со сдвигом электронной плотности $\pi$-электронов ароматической системы, включающей неподеленную пару электронов атома азота, к $\mathrm{COO}^{-}$-группе [31]. Полоса возбуждения индолкарбоксилата тербия $\mathrm{Tb}(\mathrm{ICA})_{3} \cdot 3.5 \mathrm{H}_{2} \mathrm{O}(\mathbf{1 a})$ имеет более длинноволновый край по сравнению с пирролкарбоксилатом тербия $\mathrm{Tb}(\mathrm{PCA})_{3} \cdot 3 \mathrm{H}_{2} \mathrm{O}$ из-за более протяженной $\pi-\pi$-сопряженной системы. Гипсохромный сдвиг полосы в индолпропионате тербия $\mathrm{Tb}(\mathrm{IPA})_{3} \cdot \mathrm{H}_{2} \mathrm{O}$ (3a) по сравнению с 1а связан с ослаблением сопряжения системы $\pi$-электронов метиленовыми мостиками $-\left(\mathrm{CH}_{2}\right)_{2}-$.

Очень низкая интенсивность полос лиганда и узких линий иона $\mathrm{Eu}^{3+}$ в области короче $390 \mathrm{~nm}$ 
в спектрах возбуждения $\mathrm{Eu}(\mathrm{ICA})_{3} \cdot 3.5 \mathrm{H}_{2} \mathrm{O} \quad$ (1) $\mathrm{Eu}(\mathrm{IAA})_{3} \cdot 1.5 \mathrm{H}_{2} \mathrm{O}$ (2) (рис. 4), как и в спектрах пиррол-2-карбоксилата европия $\mathrm{Eu}(\mathrm{PCA})_{3} \cdot 3 \mathrm{H}_{2} \mathrm{O}$, относится к тушению люминесценции с участием состояния LMCT. В пирролкарбоксилате наблюдается уменьшение интенсивности линий перехода ${ }^{7} F_{0}-{ }^{5} L_{6}$ иона $\mathrm{Eu}^{3+}$ при комнатной температуре, в то время как спектры возбуждения индолкарбоксилатов 1 и $\mathbf{2}$ при $295 \mathrm{~K}$ зарегистрировать не удалось из-за крайне слабой люминесценции. Принимая во внимание температурное поведение времени жизни ${ }^{5} D_{0}$-состояния и интенсивности люминесценции двойных индолкарбоксилатов европия (таблица), отличающееся от поведения этих характеристик для изоструктурных соединений тербия, можно предположить, что в первых минимум потенциальной кривой LMCT находится ниже ${ }^{5} D_{0}$-состояния, что способствует опустошению последнего. Судя по спектроскопическим данным, энергия LMCT, как и энергия активации (составляющая $\sim 3900 \mathrm{~cm}^{-1}$ для пиррол-2-карбоксилата [10]) не должны сильно отличаться в индол-3-карбоксилате 1 и пиррол-2-карбоксилате, в то время как в индол-3-ацетате 2 и индол-3-пропионате 3 энергия активации должна быть более низкой.

В большинстве тройных соединений лантанидов и, в частности, в индолкарбоксилатах европия и тербия с $2,2^{\prime}$-бипиридином (рис. 5), полоса возбуждения расширяется в длинноволновый диапазон до $\sim 400 \mathrm{~nm}$. Так как длинноволновый край полосы Phen и Вру в спектрах возбуждения обычно лежит около $\sim 350$ и $\sim 325 \mathrm{~nm}$ соответственно, то это расширение обусловлено изменением прочности связывания лиганда индолкарбоксилата в кристаллической решетке при образовании тройных соединений. Сдвиг полосы может быть связан как с повышением донорной способности ароматической системы лиганда, так и с повышением акцепторной способности $\mathrm{COO}^{-}$-группы. Аналогичное расширение полосы возбуждения флюоресценции прослеживается и в индол-3-пропионате цинка с 1,10-фенантролином [21].

В отличие от соединения $\mathrm{Tb}(\mathrm{ICA})_{3}$. Вру $(\mathbf{5})$, имеющего широкую полосу возбуждения как при 77, так и при $295 \mathrm{~K}$, в соединениях европия $\mathrm{Eu}(\mathrm{ICA})_{3}$. Bру (4) и $\mathrm{Eu}(\mathrm{IPA})_{3}$. Вру (9) при $295 \mathrm{~K}$ наблюдается падение интенсивности полосы лигандов и линий высокочастотных переходов иона $\mathrm{Eu}^{3+}$. В процесс передачи энергии возбуждения включаются тушащие состояния LMCT. Как отмечалось выше, при изменении температуры от 77 до $295 \mathrm{~K}$ интенсивность люминесценции уменьшилась в обоих соединениях европия, но время жизни сократилось только в 9. Это указывает на более высокое положение уровня LMCT в соединении 4 и обратную передачу энергии возбуждения предположительно с триплета лиганда ICA на LMCT с ее дальнейшей деградацией в кристаллическую решетку в отличие от тушения ${ }^{5} D_{0}$-состояния в 9. В этих соединениях при возбуждении в полосу поглощения Вру может осуществляться передача энергии с синглетного состояния Вру $\left(\sim 30500 \mathrm{~cm}^{-1}\right)$ на синглет индолкарбоксилата $\left(\sim 25500-27000 \mathrm{~cm}^{-1}\right)$ с

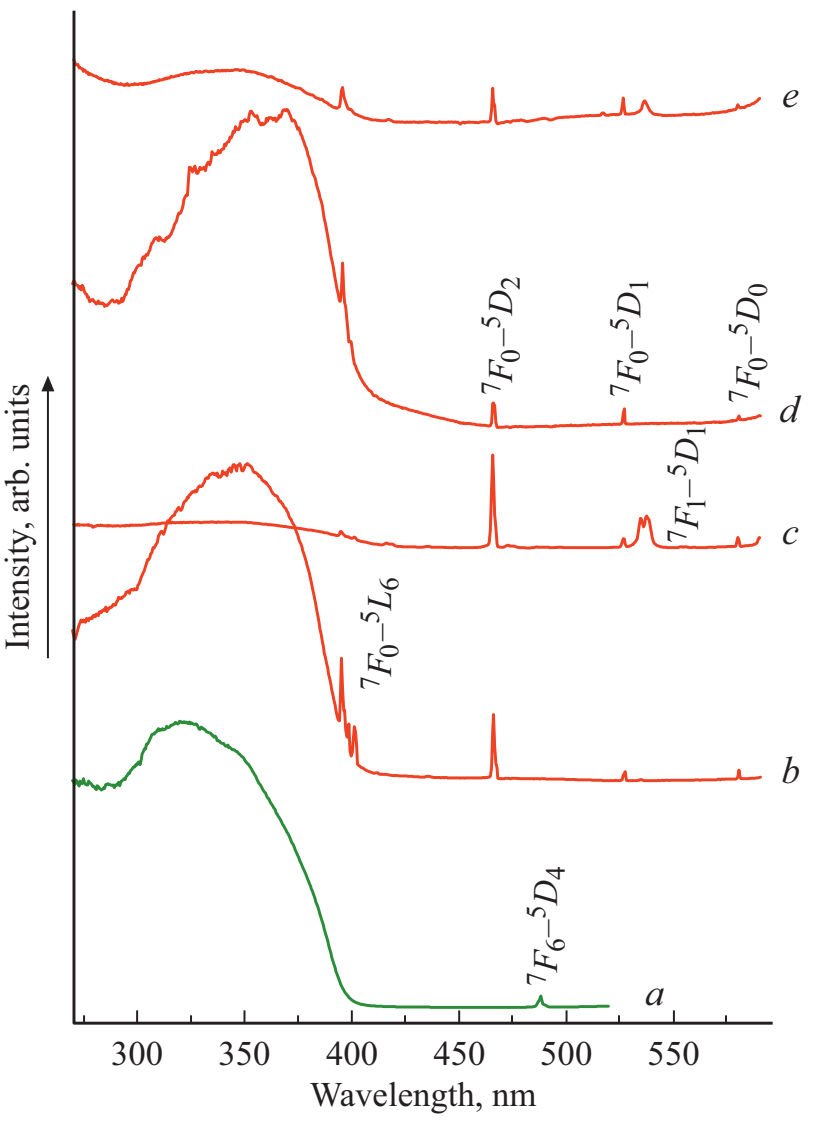

Рис. 5. Спектры возбуждения люминесценции тройных индолкарбоксилатов: $\mathrm{Tb}(\mathrm{ICA})_{3}$. Вру (5) при $77(a), \operatorname{Eu}(\mathrm{ICA})_{3} \cdot$ Bру (4) при $77(b)$ и $295 \mathrm{~K}(c), \mathrm{Eu}(\mathrm{IPA})_{3}$. Вру $(9)$ при $77(d)$ и $295 \mathrm{~K}(e)$.

последующим тушением по двум разным механизмам. O более высокой энергии LMCT и более высокой энергии активации в тройных соединениях европия по сравнению с двойными свидетельствует наличие полосы лигандов в первых при $77 \mathrm{~K}$ и ее отсутствие во вторых.

В отличие от исследованных ранее пиридинкарбоксилатов лантанидов [32], в которых неподеленная пара электронов атома азота не взаимодействует с системой $\pi$-электронов пиридинового кольца из-за ортогональной ориентации орбиталей [31], в индолкарбоксилатах, как и в пирролкарбоксилатах, p-орбиталь атома азота включена в сопряжение с системой $\pi$-электронов гетероцикла благодаря параллельной ориентации орбиталей. Дектет электронов, распределенный по девяти атомам системы двух циклов индол-3-карбоксилата, и секстет электронов, распределенный по пяти атомам цикла пиррол-2-карбоксилата, обеспечивают избыток электронной плотности в ароматической системе, за счет которого появляются низкоэнергетические состояния LMCT в соединениях европия. В пиридинкарбоксилатах европия нет избытка электронной плотности в лиганде по сравнению с этими системами, поэтому LMCT-состояние, являющееся высокоэнергетическим, не идентифицировано [32]. Спектры возбуждения люминесценции 
пиридинкарбоксилатов европия и тербия идентичны в области электронных полос лиганда и слабо зависят от температуры.

\section{Выводы}

Изучены процессы возбуждения люминесценции в индол-3-карбоксилатах $\operatorname{Ln}(\mathrm{ICA})_{3} \cdot 3.5 \mathrm{H}_{2} \mathrm{O}$, индол-3-ацетатах $\operatorname{Ln}(\mathrm{IAA})_{3} \cdot 1.5 \mathrm{H}_{2} \mathrm{O}$ и индол-3-пропионатах $\mathrm{Ln}(\mathrm{IPA})_{3} \cdot \mathrm{H}_{2} \mathrm{O} \quad(\mathrm{Ln}=\mathrm{Eu}, \quad \mathrm{Tb}), \quad$ а также в серии тройных индолкарбоксилатов европия и тербия с 1,10-фенантролином и 2,2'-бипиридином. Проанализированы спектры возбуждения люминесценции, времена жизни состояний ${ }^{5} D_{0}\left(\mathrm{Eu}^{3+}\right)$ и ${ }^{5} D_{4}\left(\mathrm{~Tb}^{3+}\right)$ и интенсивность люминесценции. Колебательные ИК спектры свидетельствуют об одинаковом строении двойных соединений европия и тербия с каждой из трех индолкарбоновых кислот. Во всех двойных

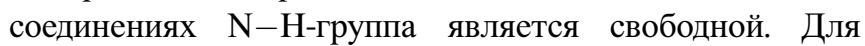
тройных соединений характерно разное строение с сетью водородных связей, образованных N-H-группами.

Продемонстрирована первостепенная роль состояний LMCT в передаче энергии возбуждения к иону $\mathrm{Eu}^{3+}$ и тушении люминесценции ароматических карбоксилатов европия, содержащих пиррольный или индольный фрагмент. Сопряжение параллельно ориентированных орбиталей неподеленной пары электронов атома азота и системы $\pi$-электронов ароматического фрагмента лиганда создает избыток электронной плотности, который в индол-3-карбоксилатах, как и в пиррол-2-карбоксилатах, может сместиться к иону $\mathrm{Eu}^{3+}$ с образованием низкоэнергетических состояний LMCT. В индол-3-ацетатах и индол-3-пропионатах формирование состояний LMCT модифицировано метиленовыми мостиками. В исследованных соединениях европия с $\pi$-избыточными лигандами активны два канала тушения люминесценции с участием LMCT. Для большинства соединений европия характерно тушение, обусловленное безызлучательной дезактивацией ${ }^{5} D_{0}$-состояния иона $\mathrm{Eu}^{3+}$ через низкоэнергетическое состояние переноса заряда „лиганд-металл“. Но в некоторых тройных соединениях состояние переноса заряда, будучи более высокоэнергетическим, участвует в опустошении возбужденных электронных состояний лиганда.

\section{Благодарности}

Авторы благодарны к.Х.н. В.А. Кудряшовой за синтезы исследованных в работе соединений. Авторы также признательны проф. Янине Легендзевич (Вроцлавский университет, Польша) за предоставленную возможность измерения спектров возбуждения люминесценции в ее лаборатории.

\section{Финансирование работы}

Работа выполнена в рамках государственного задания Министерства науки и высшего образования Российской федерации.

\section{Конфликт интересов}

Авторы заявляют, что у них нет конфликта интересов.

\section{Список литературы}

[1] G.F. de Sá, O.L. Malta, C. de Mello Donegá, A.M. Simas, R.L. Longo, P.A. Santa-Cruz, E.F. da Silva Jr. Coord. Chem. Rev., 196 (1), 165 (2000).

DOI: 10.1016/S0010-8545(99)00054-5

[2] G.K. Liu, M.P. Jensen, P.M. Almond. J. Phys. Chem. A., 110 (6), 2081 (2006). DOI: 10.1021/jp0558674

[3] S. Petoud, J.-C.G. Bünzli, T. Glanzman, C. Piguet, Q. Xiang, R.P. Thummel. J. Lumin., 82 (1), 69 (1999). DOI: $10.1016 / \mathrm{S} 0022-2313(99) 00015-0$

[4] W.M. Faustino, O.L. Malta, G.F. de Sá. J. Chem. Phys., 122, 054109 (2005). DOI: $10.1063 / 1.1830452$

[5] W.M. Faustino, O.L. Malta, G.F. de Sá. Chem. Phys. Lett., 429 (4-6), 595 (2006). DOI: 10.1016/j.cplett.2006.08.059

[6] D.V. Lapaev, V.G. Nikiforov, V.S. Lobkov, A.A. Knyazev, Yu.G. Galyametdinov. Opt. Mater., 75, 787 (2018). DOI: 10.1016/j.optmat.2017.11.042

[7] K. Yanagisawa, Y. Kitagawa, T. Nakanishi, T. Seki, K. Fushimi, H. Ito, Y. Hasegawa. Chem. Eur. J., 24 (8), 1956 (2018). DOI: $10.1002 /$ chem.201705021

[8] V.I. Tsaryuk, K.P. Zhuravlev. J. Lumin., 237, 118159 (2021). DOI: $10.1016 /$ j.jlumin.2021.118159

[9] V. Tsaryuk, K. Zhuravlev, V. Kudryashova, V. Zolin, J. Legendziewicz, I. Pekareva, P. Gawryszewska. J. Photochem. Photobiol. A: Chem., 197 (2-3), 190 (2008). DOI: $10.1016 /$ j.jphotochem.2007.12.022

[10] K.P. Zhuravlev, Ł. Michnik, P. Gawryszewska, V.I. Tsaryuk, V.A. Kudryashova. Inorg. Chim. Acta., 492, 1 (2019). DOI: 10.1016/j.ica.2019.04.014

[11] A. Tine, P. Valat, J.J. Aaron. J. Lumin., 36 (2), 109 (1986). DOI: $10.1016 / 0022-2313(86) 90059-1$

[12] A.K. Solanki, A.M. Bhandari. J. Inorg. Nucl. Chem., 41 (9), 1311 (1979). DOI: 10.1016/0022-1902(79)80045-7

[13] F.-Y. He, L. Wang, Zh. Chen, J. Wu. Synth. React. Inorg. Met.-Org. Chem., 24 (4), 575 (1994). DOI: $10.1080 / 00945719408000134$

[14] G.-L. Law, K.-L. Wong, K.-K. Lau, H.-L. Tam, K.-W. Cheah, W.-T. Wong. Eur. J. Inorg. Chem., 2007 (34), 5419 (2007). DOI: $10.1002 /$ ejic.200700584

[15] Z.-N. Wang, X.-T. Xu, X. Lv, F.-Y. Bai, S.-Q. Liu, Y.-H. Xing. RSC Adv., 5(126), 104263 (2015). DOI: $10.1039 / C 5 R A 19376 A$

[16] Y. Shimazaki, T. Yajima, M. Takani, O. Yamauchi. Coord. Chem. Rev., 253 (3-4), 479 (2009). DOI: $10.1016 /$ j.ccr.2008.04.012

[17] V. Viossat, P. Lemoine, E. Dayan, N.-H. Dung, B. Viossat. J. Mol. Struct., 741 (1-3), 45 (2005). DOI: $10.1016 /$ j.molstruc.2005.01.040

[18] B. Morzyk-Ociepa. Vibr. Spectrosc., 49(1), 68 (2009). DOI: 10.1016/j.vibspec.2008.04.014 
[19] K. Szmigiel-Bakalarz, A. Skoczyńska, M. Lewańska, D. Günther, O. Oeckler, M. Malik-Gajewska, D. Michalska, B. Morzyk-Ociepa. Polyhedron., 185, 114582 (2020). DOI: $10.1016 /$ j.poly.2020.114582

[20] M. Cinar, M. Karabacak, A.M. Asiri. Spectrochim. Acta A., 137, 670 (2015). DOI: 10.1016/j.saa.2014.08.090

[21] X.-J. Deng, Q. Yu, H.-D. Bian, H.-D. Ju, B.-L. Wang. Trans. Met. Chem., 41, 591 (2016). DOI: $10.1007 / \mathrm{s} 11243-016-0057-0$

[22] T.V. Sravanthi, S.L. Manju. Eur. J. Pharm. Sci., 91, 1 (2016). DOI: 10.1016/j.ejps.2016.05.025

[23] A. Kumari, R.K. Singh. Bioorg. Chem., 89, 103021 (2019). DOI: 10.1016/j.bioorg.2019.103021

[24] R.K. Bauer, P. de Mayo, W.R. Ware, K.C. Wu. J. Phys. Chem., 86 (19), 3781 (1982). DOI: 10.1021/j100216a016

[25] A. Tine, Ph. Guillaume, A. Massat, J.-J. Aaron. Spectrochim. Acta A., 54 (10), 1451 (1998). DOI: $10.1016 / \mathrm{S} 1386-1425(98) 00046-8$

[26] K. Zhuravlev, V. Tsaryuk, V. Kudryashova, I. Pekareva, J. Sokolnicki, Yu. Yakovlev. J. Lumin., 130 (8), 1489 (2010). DOI: 10.1016/j.jlumin.2010.03.018

[27] M.H.V. Werts, R.T.F. Jukes, J.W. Verhoeven. Phys. Chem. Chem. Phys., 4 (9), 1542 (2002). DOI: 10.1039/B107770H

[28] V.I. Tsaryuk, K.P. Zhuravlev, A.V. Vologzhanina, V.A. Kudryashova, V.F. Zolin. J. Photochem. Photobiol. A: Chem., 211 (1), 7 (2010). DOI: 10.1016/j.jphotochem.2010.01.012

[29] F.R. Gonçalves e Silva, R. Longo, O.L. Malta, C. Piguet, J.-C.G. Bünzli. Phys. Chem. Chem. Phys., 2 (23), 5400 (2000). DOI: $10.1039 / \mathrm{B} 005624 \mathrm{~N}$

[30] K.P. Zhuravlev, V.I. Tsaryuk, V.A. Kudryashova. J. Fluorine Chem., 212, 137 (2018). DOI: 10.1016/j.jfluchem.2018.06.002

[31] Свердлова О.В. Электронные спектры в органической химии (Химия, Ленинградское отд., Ленинград, 1985).

[32] V.F. Zolin, L.N. Puntus, V.I. Tsaryuk, V.A. Kudryashova, J. Legendziewicz, P. Gawryszewska, R. Szostak. J. Alloys Compd., 380 (1-2), 279 (2004).

DOI: $10.1016 /$ j.jallcom.2004.03.055 